\title{
Nilai Perlambatan Dan Uji Ketegangan Disch Brake Pada Sistem Pengereman (Gokart 7,5 Hp)
}

\author{
Afiff Yudha Tripariyanto ${ }^{1}$, Lolyka Dewi ${ }^{2}$, Ana Komari ${ }^{3}$ \\ 1,2,3,Program Studi Teknik Industri, Universitas Kadiri, Jl Selomangleng No.1 Kediri,64115 \\ Correspondence: Afiff Yudha Tripariyanto (afiff@unik-kediri.ac.id) \\ (081359835826)
}

Received: 010821 - Revised: 150821 - Accepted: 100921 - Published: 150921

\begin{abstract}
Abstrak. Setiap kendaraan baik kendaraan yang kita pakai sehari hari sampai ke kendaraan sport untuk balapan di lintasan akan dilengkapi dengan system Pengereman. Pengereman merupakan salah satu piranti penting dalam sebuah kendaraan bermotor baik Roda dua maupun roda empat dan seterusnya. Secara sederhana Fungsi dari pengereman untuk mengurangi laju kendaraan dari kecepatan tinggi ke rendah dan sampai benar-benar berhenti. Dalam system pengereman dibagai menjadi 2 yaitu disch brake dan drum brake yang membedakan keduanya terletak pada cara kerjanya dan jenis komponenya. Metode yang digunakan dalam penelitian ini adalah menggunakan metode secara langsung yaitu mulai mempersiapkan alat dan bahan serta melakukan pengujian secara langsung yaitu pemasangan pengeraman disch brake pada Gokart Daiho 7,5 Hp yang peletakanya dilakukan pada poros belakang dengan menghitung centroid/titik tengah sehingga didapatkan balancing yang sesuai. Dalam penelitian ini akan menganalisa aplikasi nilai perlambatan pengereman disch brake pada Gokart Daiho 7,5 Hp dengan beberapa variasi kecepatan awal yang berbeda yitu dimulai dari nilai kecepatan terkecil 20,30,40,50,60 dengan nilai perlambatan pengereman adalah 80,75,94,11,125 dan $150 \mathrm{~m} / \mathrm{dtk}$ dengan waktu pengereman 0,25. 0,4. 0,425.0,4.0,4 dan 0,4.,efisiensi pengereman sebesar 13,58\% dengan nilai tegangan pengereman sebesar $0,26 \mathrm{~m}^{2}$. dari hasil nilai tersebut maka bisa ditarik kesimpulan bahwa semakin tinggi nilai kecapatan kendaraan maka juga akan semakin lama waktu yng digunakan untuk memberhentikan kendaraan tersebut dan jarak pengeremanpun juga akan semakin panjang.
\end{abstract}

Kata kunci: Disch Brake, Kecepatan, Perlambatan, Tegangan

Citation Format: Tripariyanto. A,P., Dewin. L., Komari. (2021). Nilai Perlambatan Dan Uji Ketegangan Disch Brake Pada Sistem Pengereman (Gokart 7,5 Hp). Prosiding Seminar Nasional Abdimas Ma Chung (SENAM), 2020, 59-73 


\section{PENDAHULUAN}

Sistem pengereman merupakan piranti yang sangat penting dalam kendaraan bermotor baik roda dua maupun roda empat atau lebih. dengan piranti pengereman tersebut pengendara akan dijamin keamanan dan keselamatan saat berkendara baik dijalan lurus, lintasan balap maupun di jalan terjal dan tidak datar. Saat melaju dengan kecepatan tinggi, sedang maupun lambat sebuah kendaraan harus bisa berhenti dengan baik dan sesuai dengan prediksi pengendara. Secara umum, sistem rem merupakan komponen yang akan menunjang keselamatan dalam berkendara. Pasalnya, komponen ini berperan dalam pengurangan laju kendaraan. Gesekan (friction) merupakan faktor utama dalam pengereman. Oleh karena itu komponen yang dibuat untuk sistem rem harus mempunyai sifat bahan yang tidak hanya menghasilkan jumlah gesekan yang besar, tetapi juga harus tahan terhadap gesekan dan tidak menghasilkan panas yang dapat menyebabkan bahan tersebut meleleh atau berubah bentuk. Bahan yang tahan terhadap gesekan tersebut biasanya merupakan gabungan dari beberapa bahan (komposit) yang disatukan dengan melakukan perlakuan tertentu. Sejumlah bahan tersebut antara lain tembaga, kuningan, timah, grafit, karbon, kevlar, resin/damar, fiber dan bahan aditif/tambahan lainnya. Rem cakram (disch brake) merupakan perangkat pengereman pada kendaraan yang tersusun dari piringan yang terbuat dari logam. Piringan logam akan dijepit oleh kampas rem yang didorong oleh sebuah torak yang berada dalam silinder roda. Dalam menjepit piringan ini, kampas rem membutuhkan tenaga yang kuat karena piringan ini sangat kuat pula. Oleh karena itu rem cakram telah dilengkapi dengan sistem hidrolik (minyam rem yang mengalir dari handle tekanan kaki menuju ke piringan cakram. Sesuai dengan bentuk dan fungsinya rem cakram merupakan sistem pengereman yang bekerja dengan cara menjepit piringan cakram yang terpasang pada bagian roda kendaraan untuk mengurangi dan menghentikan putaran pada roda kendaraan. Sistem rem cakram ini memiliki penampang rem yang lebih kecil dibanding system lainnya namun memiliki daya gesek sangat kuat yang saling menekan gaya gesekan sehingga proses pengereman lebih efektif. Maka dari sistem ini diklaim lebih sederhana dan lebih responsif dibandingkan dengan jenis rem yang lainnya. Rem merupakan suatu komponen pendukung pada kendaraan bermotor yang berfungsi untuk mendisipasi energi gerak kendaraan sehingga kendaraan mengalami perlambatan. Prinsip kerja dari rem ini yaitu adanya gesekan antara piringan dengan kampas rem pada saat kedua komponen rem ini berkontak. Alur dalam proses gaya gesek tersebut, energi kinetik dari kendaraan diubah menjadi panas dan 
bunyi pada saat rem beroperasi (Meifal Dkk, 2010). Beberapa komponen dalam disch brake adalah sebagai berikut :

\section{A. Disc Brake / Piringan rem}

Komponen pertama pada rem cakram/disc brake atau piringan rem. Fungsi piringan adalah sebagai media yang digunakan untuk penekanan dari kampas rem agar dapat menimbulkan efek braking. Piringan rem ini berbahan baja karena komponen ini memang harus menahan panas yang dihasilkan dari gesekan yang terjadi dari kampas pada saat proses pengereman. Piringan rem memiliki dua jenis.

a. Ventilated Disc, memiliki lubang disekitar piringan dan biasanya memiliki bentuk yang lebih tipis. Lubang ini akan dimaksimalkan demi proses pendinginan piringan yang panas akibat gesekan. Jenis ventilated disc ini kebanyakannya diaplikasikan pada rem cakram sepeda motor.

b. Solid Disc, Piringan ini berbahan besi baja pula namun ketebalan yang dimiliki lebih besar dan tidak terdapat lubang disekitarnya. Hal ini berpengaruh pada daya pengereman agar lebih kuat. solid disc ini akan kita temui pada rem cakram mobil.

\section{B. Kampas Rem}

Brake pad atau kampas rem merupakan komponen yang berfungsi untuk menekan piringan rem tatkala proses pengereman dilakukan. Demi menghasilkan pengereman yang maksimal, kampas rem harus mempunyai gaya gesek yang besar dan dapat harus dapat menahan panas. Kampas rem dulunya terbuat dari bahan asbes,namun ketika penggunaan asbes pada komponen otomotif dilarang karena debu asbes sangat berbahaya bagi kesehatan manusia. Maka dari itu, saat ini bahan yang marak digunakan adalah paduan keramik dengan serbuk besi. Bahan tersebut lebih ramah lingkungan serta gesekan yang dihasilkan menjadi lebih besar dengan panas yang wajar.

\section{Caliper Rem}

Caliper rem adalah komponen pengubah tekanan fluida menjadi gerakan mekanis yang akan menekan brake pad. Singkatnya fungsi rem cakram adalah mengubah tekanan hidraulik yang masuk ke kaliper menjadi gerakan mekanis untuk menjepit brake pad. 


\section{Booster Rem}

Komponen ini memiliki fungsi sebagai assist untuk meringankan penekanan pedal rem tanpa mengurangi daya pengereman yang ada. booster rem ini dapat melipat gandakan energi pengereman yang digunakan. booster rem dibuat dari membran yang dihubungkan dengan intake manifold. Jika terdapat kevakuman pada intake manifold, maka membran yang terhubung dengan master silinder ini akan menarik pedal rem, namun tarikan tersebut tidak sampai melakukan pengereman pada roda kendaraan anda. Ketika pengemudi mulai menginjak pedal rem, maka akan terasa sangat ringan. Hal tersebut dapat terjadi disebabkan proses yang terjadi telah dibantu dengan tarikan membran booster rem. Kemudian pada mesin diesel umumnya menggunakan pompa vakum karena kevakuman di intake manifold diesel kurang signifikan.

\section{E. Master silinder}

Komponen ini memiliki fungsi untuk mengubah gerakan mekanis pedal rem menjadi sebuah tekanan hidraulis. Master silinder memiliki komponen berupa piston yang terhubung dengan pedal rem. Piston ini akan yang akan menekan fluida berdasarkan hukum pascal.

\section{F. Reservoir}

Bagian terakhir pada pembahasan ini adalah reservior. Bagian ini merupakan komponen yang memiliki fungsi untuk menampung fluida atau minyak rem cadangan. Tabung reservoir menyatu dengan master silinder. dalam tabung ini biasanya memiliki sebuah sensor yang berfungsi mendeteksi level volume minyak rem.

Cara kerja Rem Cakram/Disch Brake dalam sebuah kendaraan adalah dengan melakukan tekanan dan jepitan pada piringan akan dijelaskan sebagai berikut :

1. Rem akan bekerja karena posisi kita injak pedal, dari injakan tersebut piston pada master rem akan tertekan dan terdorong kedepan.

2. Tekanan pada minyak rem yang diteruskan lewat selang rem ke piston yang mengakibatkan kampas rem terdorong. Sehingga kampas rem akan mencengkram piringan cakram.

3. Dari proses tersebut terjadi pengereman sehingga memperlambat laju motor.

4. Setelah kita melepaskan pedal rem akan menyebabkan adanya peregangan sehingga tidak ada gesekan antara kampas rem dan piringan. 


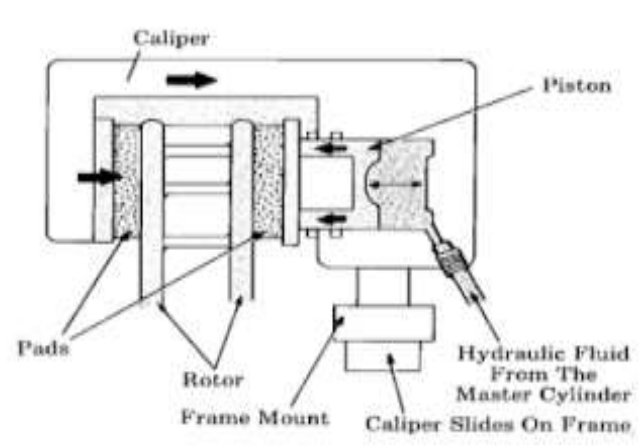

Floating caliper

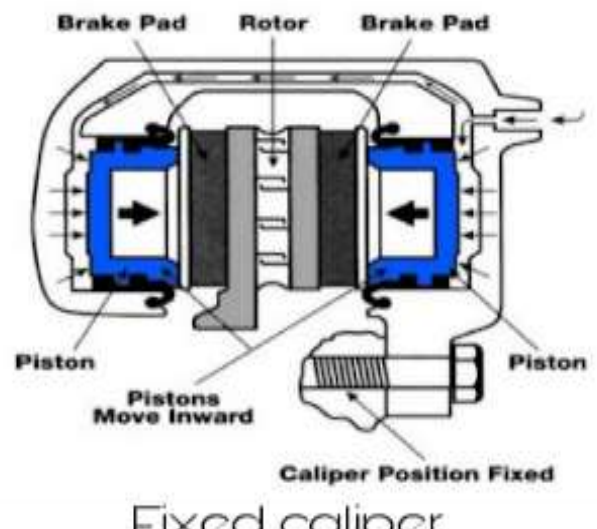

Fixed caliper

Gambar 1. Disch Berdasarkan Caliper.

\section{a. Tipe Fixed Caliper}

Sesuai dengan namanya, rem cakram tipe fixed caliper mengacu pada rem cakram dengan kaliper tetap (fixed). Disebut kaliper tetap karena posisinya tidak akan berubah saat bekerja, baik saat melakukan pengereman maupun tidak (bebas). Pada struktur fixed caliper, terdapat dua buah piston yang bergerak berlawanan satu sama lain. Setiap piston memiliki saluran hidrolik yang terhubung ke konektor saluran masuk hidrolik (nipple inlet hydraulic). Dengan begitu, saat rem diinjak, kedua piston akan terjepit. Gerakan menjepit akan menekan kedua bantalan rem untuk menjepit cakram rem.

\section{b. Tipe Floating Caliper}

Sedangkan untuk tipe floating caliper, tipe ini memiliki kaliper rem mengambang (floating). Disebut mengambang karena posisi kaliper rem bisa bergerak ke kiri dan ke kanan sesuai dengan tekanan yang diberikan ke pedal rem. Hanya ada satu piston di satu sisi struktur kaliper floating dan hanya juga satu saluran hidraulik. Namun posisi pin kaliper tidak dibaut ke braket kaliper. Dengan begini, kaliper bisa bergerak bebas ke kiri dan ke kanan. Saat pedal rem ditekan, piston akan mendorong bantalan rem. Di saat yang sama, karena sifat kaliper yang bisa bergerak bebas ke kiri dan ke kanan, tekanan pada piston juga mendorong kaliper ke dalam. Dengan begitu, kedua kampas rem masih bisa menjepit piringan cakram rem.

\section{Perbedaan Fixed Caliper dengan Floating Caliper}


Secara umum, antara tipe fixed caliper dengan floating caliper memiliki perbedaan. Yaitu pada:

a) Desain fixed caliper lebih rumit, desain floating caliper sederhana.

b) Ukuran fixed caliper lebih besar dari pada ukuran floating caliper Kekuatan pengereman fixed caliper lebih besar dibandingkan kekuatan floating caliper.

c) Floating caliper lebih awet karena memiliki sedikit gesekan komponen dari pada fixed caliper.

d) Fixed caliper digunakan pada mobil ukuran besar seperti Big SUV/Double Cab dan offroader, floating caliper dipakai pada MPV, Sedan, Hatchback, serta Mini/Mid SUV.

Kendaraan tidak dapat berhenti dengan segera apabila mesin dibebaskan [tidak dihubungkan] dengan pemindahan daya. Kendaraan cenderung tetap bergerak. Kelemahan ini harus dikurangi dengan maksud untuk menurunkan kecepatan gerak hingga berhenti. Mesin merubah energi panas menjadi energi kinetis (energi gerak) ntuk menggerakkan kendaraan. Sebaliknya rem merubah energi kinetis kembali menjadi energi panas untuk menghentikan kendaraan. Umumnya rem bekerja disebabkan oleh adanya sistem gabungan penekanan melawan sistem gerak putar. Efek pengereman (braking effect) diperoleh dari adanya gesekan yang ditimbulkan antara dua obyek. Beberapa peneliti menyatakan bahwa, rem cakram/Disch brake aus lebih cepat dan kehilangan kemampuannya terutama pada kendaraan modern, walaupun pemakaian kendaraan tersebut masih kurang dari $40.000 \mathrm{~km}$. Keausan dini rem tersebut karena brake pad yang modern lebih abrasif karena compound yang keras, juga kualitas buruk rem cakram yang diimpor dari beberapa negara Asia Timur (Ian Hardianto Siahaan, 2008). Dari pendahuluan diatas maka penelitian sistem pengeraman disch brake ini akan diaplikasikan pada perancangan Gokart Daiho dengan kapasitas mesin 7,5 Hp. Dimana gokart merupakan kendaraan dengan jenis sport yang digunakan pada lintasan balap/sirkuit dengan kecepatan tertentu. Gokart sendiri di desain dengan body dan berat seringan mungkin agar didapatkan laju kendaraan yang maksimal sehingga waste yang diterima oleh mesin lebih sedikit. dan juga untuk mengetahui nilai perlambatan system pengereman Gokart pada saat di uji dilintasan berkelok apakah disch brake yang dipasang pada Gokart tersebut 
bisa mengurangi laju dan benar-benar sampai berhenti dan ketegangan sistem disch brake.

\section{METODE PELAKSANAAN}

Dalam Penelitian ini dijelaskan dalam beberapa langkah yaitu sebagai berikut :

adapun metoda penelitian yang dilakukan meliputi studi literatur, observasi, dan percobaan percepatan Gokart Daiho, serta pembahasan hasil dari penelitian. Secara rinci dapat diuraikan sebagai berikut:

a) Studi literatur, dilakukan untuk pengumpulan data-data mengenai perlamabatan sistem Pengereman dan Spesifikasi Gokart Daiho 7,5 Hp.

b) Observasi lapangan, bertujuan melihat langsung efektifitas dan efisiensinya hanya terhadap waktu, cara kerja dan tenaga kerjanya.

c) Pengambilan data pengujian mekanik penelitian ini dilakukan di tempat penelitian pada saat mengambil Data Spesifikasi Gokart dan Disch Brake.

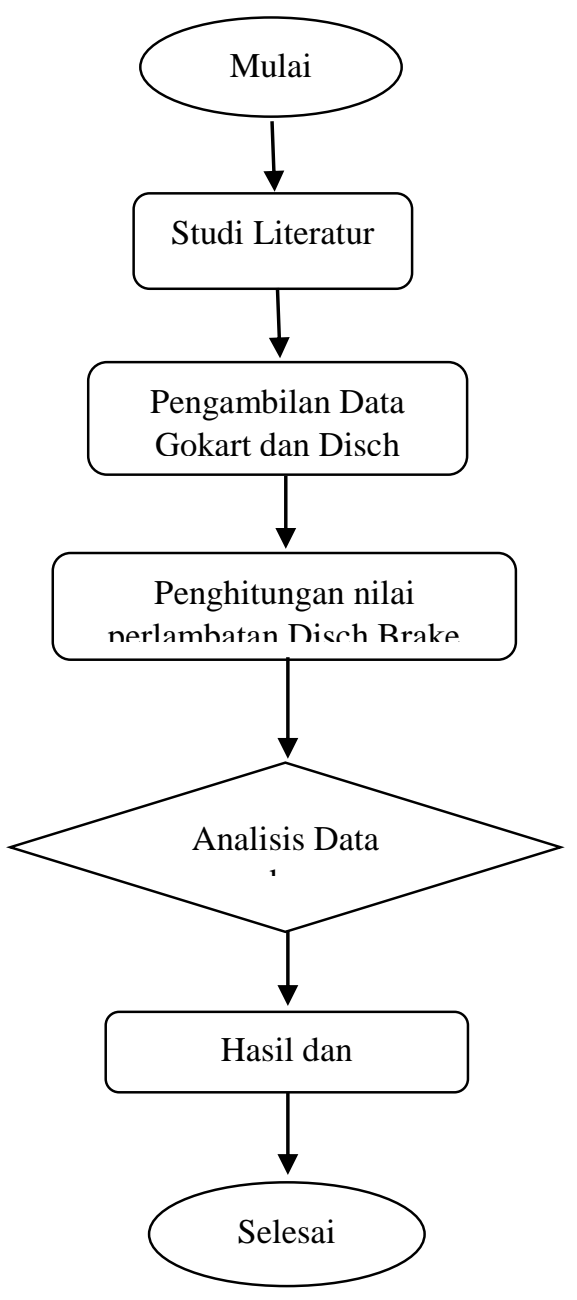




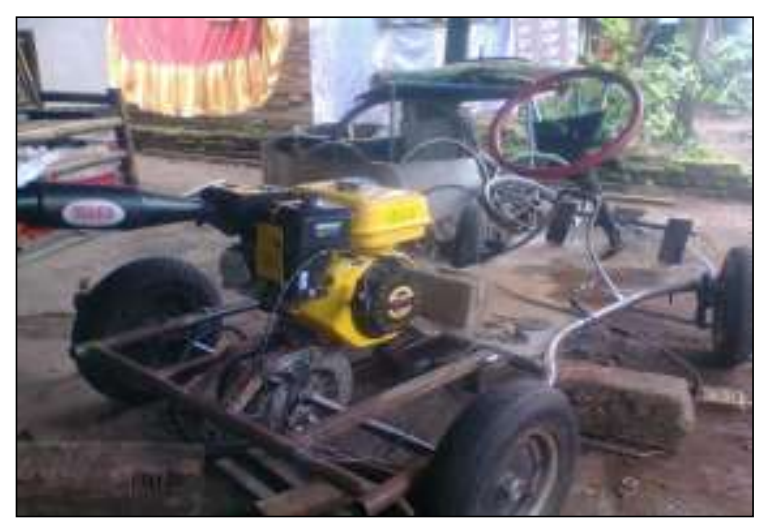

Gambar 3. Posisi Peletakan Posisi Disch Brake

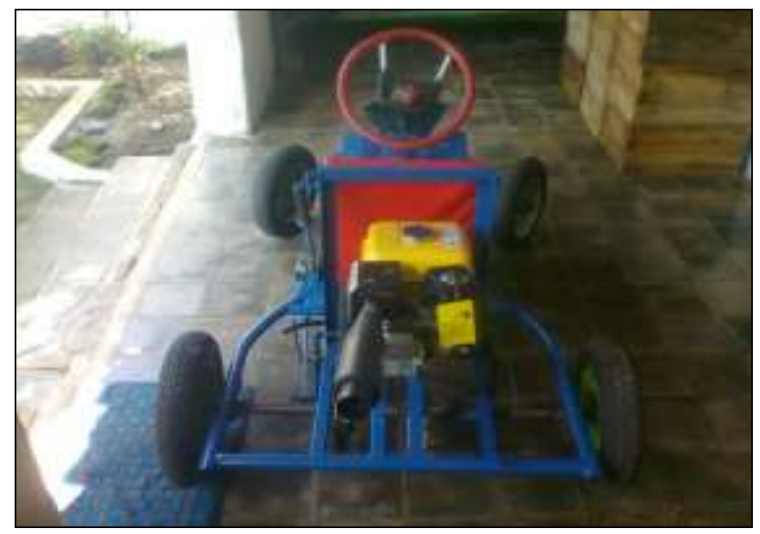

Gambar 4. Rem Disch Brake Tampak Belakang.

Tenaga penggerak utama Gokart adalah motor bakar berbahan bahan bakar premium, pertalite atau pertamax 4 langkah dengan tipe mesin Air-Cooled 4-Stroke OHV. Dengan mesin ini dapat dikeluarkan daya bersih sebesar 7.5 HP pada putaran mesin $3600 \mathrm{rpm}$. Mesin menggunakan karburator tipe butterfly dengan sistem start merupakan jenis recoil starter. Bentuk dimensi 32.1 x 37.6 x $34.6 \mathrm{~cm}$, mesin mempunyai berat bersih sekitar $16.1 \mathrm{~kg}$. Kapasitas tangki bahan bakar adalah sebesar 2.3 liter maka berat total mesin saat berisi bahan bakar adalah sekitar $18.4 \mathrm{~kg}$.

\section{Analisa Mesin}

Data dan Spesifikasi Mesin Gokart Bensin 4 langkah 7,5 HP.

a) Spesifikasi Gokart 


$\begin{array}{ll}\text { - Panjang } & : 235 \mathrm{~cm} \\ \text { - Lebar } & : 124 \mathrm{~cm} \\ \text { - Tinggi } & : 25 \mathrm{~cm} \\ \text { - Jarak antara sumbu roda } & : 170 \mathrm{~cm}\end{array}$

b) Mesin Type DAIHO $160 \mathrm{TI}$

- Vol Cylinder : $163 \mathrm{cc}$

- Bore stroke ratio : 68 x $48 \mathrm{~mm}$

- Rasio Compresi : 8,5:1

- Torsi Max $\quad: 10,3 \mathrm{n} / \mathrm{m} / 2500 \mathrm{Rpm}$

- Daya $\quad: 7,5 \mathrm{HP}$

- Type : Air cooled 4 Tak, OHV singgle Cylinder

- Tangki : 2,1 Liter

- Oli $\quad: 0,6$ Liter

- Dimensi : $312 \times 362 \times 335 \mathrm{~cm}$

c) Sistem Transmisi

- Kopling : kering sentrifugal

- Transmisi : otomatis

d) Analisis Rangka

- Bahan ( pipa kotak ) : Panjang $40 \mathrm{~mm}$ dan Lebar $20 \mathrm{~mm}$

- Rangka ( Wr ) : $50 \mathrm{~kg}$

- Mesin ( Wm ) : $18,4 \mathrm{Kg}$

- Beban : Max $68.4 \mathrm{Kg}$

e) Spesifikasi Rem (Disch Brake)

- Diameter luar piringan : $190 \mathrm{~mm}$

- Diameter dalam piringan : $76 \mathrm{~mm}$

- Tebal

Dalam proses perhitungan data jarak pengereman menggunakan rumus GLBB (gerak lurus berubah beraturan) menggunakan teorema sebagai berikut :

$$
\begin{aligned}
& \alpha=\frac{\Delta V}{\Delta t}=\frac{V 2-V 1}{t 2-t 1} m / s^{2} \\
& \mathrm{~S}=\frac{V 2^{2}-V 1^{2}}{2 \alpha}=\frac{\left(\ldots m / s^{2}-m / s^{2}\right)^{2}}{2 \alpha}
\end{aligned}
$$

Dimana :

$\alpha \quad=$ Perlambatan

$\mathrm{V} 1$ = Kecepatan awal

$\mathrm{V} 2$ = Kecepatan akhir

$\mathrm{T}=$ Waktu (s)

$\mathrm{S}=$ Jarak Pengereman 
Efisiensi Pengereman adalah Gaya pengereman yang dihasilkan sebagai presentase dari berat total Kendaraan.

Efisiensi Pengereman $=\frac{\text { Gaya } \text { Pengereman }}{\text { Berat } \text { Kendaraan }} \times 100$

Perhitungan kapasitas Pengereman total dari rem cakram untuk menghitung kapasitas pengereman dari rem cakram maka Rumus yang dipakai adalah:

$$
\mathrm{T}=\frac{F p \cdot f}{4}(D+d) \times 2
$$

Dimana :

$$
\begin{array}{ll}
\mathrm{T} & =\text { kapasitas rem }(\mathrm{kg} . \mathrm{m}) \\
\mathrm{Fp} & =\text { gaya menekan pada rem }(\mathrm{kg} . \mathrm{f}) \\
\mathrm{f} & =\text { koofisien gesek }(0,45) \text { Elemen Mesin Robert L mott } \\
\mathrm{D} & =\text { diameter Pushrood }(\mathrm{mm}) \\
\mathrm{d} & =\text { diameter piston }(\mathrm{mm})
\end{array}
$$

Menghitung Perlambatan

$$
\begin{array}{ll}
\alpha=\frac{V 0}{t} & \\
\mathrm{~V}_{0} & =\text { Kecepatan awal }(\mathrm{m} / \mathrm{dt}) \\
\mathrm{t} & =\text { waktu pengereman }(\mathrm{dt})
\end{array}
$$

Tegangan adalah besarnya gaya yang diberikan oleh molekul-molekul terhadap luasan penampang. Tegangan $(\sigma)$ besarnya gaya yang bekerja pada tiap satuan Luas penampang yang dirumuskan dengan :

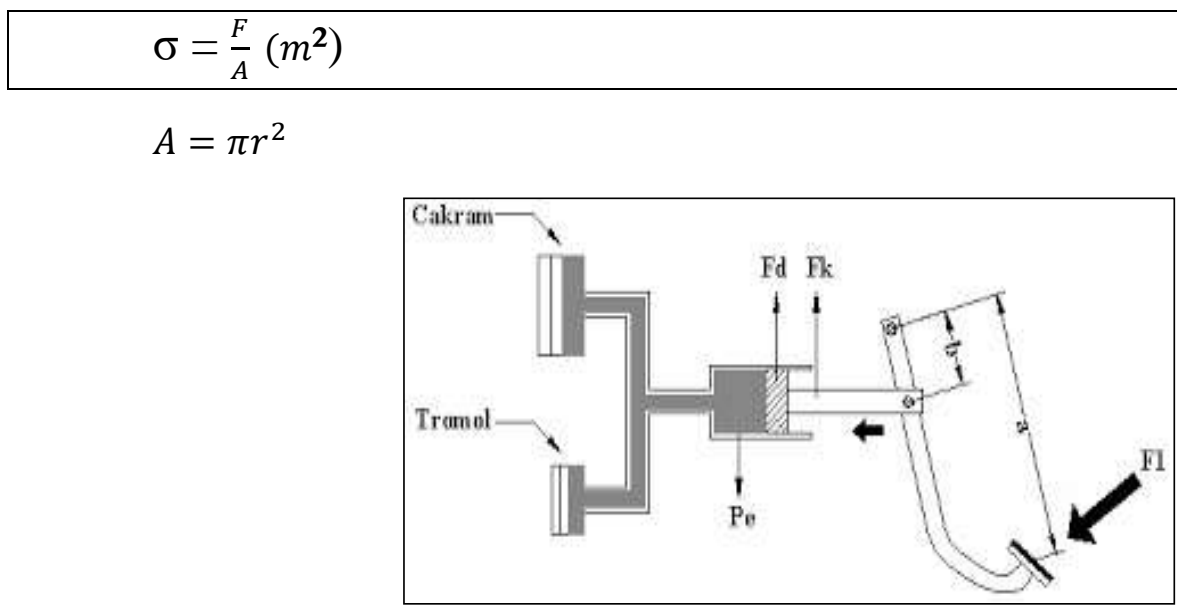

Gambar 5. Tekanan pada disch brake

Rumusan yang digunakan untuk menghitung perbandingan gaya pedal adalah sebagai berikut :

$$
K=\frac{a}{b}
$$


$\mathrm{a}=$ Jarak dari pedal rem ke Fullcrum (Tumpuan)

$\mathrm{b}=$ Jarak dari Pushrood ke Fullcrum (Tumpuan)

Untuk Kondisi Pengereman maka didapatkan Persamaan :

$$
\alpha=\frac{V o^{2}}{2 . s}=\frac{V o}{t}=\frac{2 . s}{t^{2}}
$$

$S=\frac{V o^{2}}{2 \cdot a}=\frac{V o \cdot t}{2}=\frac{a \cdot t^{2}}{2}$

$t=\frac{V o}{a}=\frac{2 . s}{V o}=\sqrt{\frac{2 . s}{a}}$

Dimana :

Vo = Kecepatan awal saat di Rem (m/dt)

$\mathrm{a}=$ perlambatan $\left(\mathrm{m} / \mathrm{dt}^{2}\right)$

$\mathrm{s}=\operatorname{jarak}(\mathrm{m})$

$\mathrm{t}=$ waktu (detik) atau $\mathrm{t}$ 


\section{HASIL DAN PEMBAHASAN}

Dari hasil yang kita ukur sesuai dengan objek yang ada maka didapatkan hasil pengukuran sebagai berikut :

Tabel 1. Data Pengukuran Disch Brake

\begin{tabular}{llcc}
\hline No & Komponen yang diukur & Hasil Pengukuran & $\begin{array}{c}\text { Tekanan Pedal } \\
(\text { F })\end{array}$ \\
\hline 1 & $\begin{array}{l}\text { a = jarak dari pedal rem ke } \\
\text { Fullcrum/Tumpuan }\end{array}$ & $136,2 \mathrm{~mm}$ & $2,5 \mathrm{~kg}, \mathrm{f}$ \\
\hline 2 & $\begin{array}{l}\text { b = jarak dari pushrod ke } \\
\text { Fullcrum }\end{array}$ & $38,2 \mathrm{~mm}$ & - \\
\hline 3 & Diameter luar piringan & $190 \mathrm{~mm}$ & - \\
\hline 4 & Diameter dalam piringan & $76 \mathrm{~mm}$ & - \\
\hline 5 & Tebal & $2,2 \mathrm{~mm}$ & - \\
\hline 6 & Diameter Pushrood /D & $11,7 \mathrm{~mm}$ & - \\
\hline 7 & Diameter Piston/d & $24,3 \mathrm{~mm}$ & - \\
\hline
\end{tabular}

Tabel 2. Data Hasil Analisa

\begin{tabular}{ccccc}
\hline No & $\begin{array}{c}\text { Kecepatan awal } \\
(\text { Vo) } \mathbf{m} / \mathbf{d t k}\end{array}$ & $\begin{array}{c}\text { Perlambatan } \\
(\mathbf{m} / \mathbf{d t k})\end{array}$ & $\begin{array}{c}\text { Jarak } \\
\text { Pengereman } \\
(\mathbf{s}) / \mathbf{m}\end{array}$ & $\begin{array}{c}\text { Waktu } \\
\text { pengereman } \\
(\mathbf{t})\end{array}$ \\
\hline 1 & 20 & 80 & 2,5 & 0,25 \\
\hline 2 & 30 & 75 & 6 & 0,4 \\
\hline 3 & 40 & 94,11 & 8,5 & 0,425 \\
\hline 4 & 50 & 125 & 10 & 0,4 \\
\hline 5 & 60 & 150 & 12 & 0,4
\end{tabular}

Hasil Perbandingan antara gaya pedal adalah sebagai berikut:

$$
K=\frac{a}{b}=
$$


$\mathrm{K}=\frac{136,2}{38,2}=3,56$

Efisiensi Pengereman $=\frac{\text { Gaya } \text { Pengereman }}{\text { Berat } \text { Kendaraan }} \times 100$

$$
=\frac{2,5}{18,4} \times 100=13,58 \%
$$

Nilai perhitungan kapasitas pengereman total dari rem cakram untuk menghitung kapasitas pengereman dari Rem cakram adalah sebagai berikut :

$$
\begin{aligned}
& \mathrm{T}=\frac{F p \cdot f}{4}(D+d) \times 2 \\
& \mathrm{~T}=\frac{2,5 \cdot 0,45}{4}(11,7+24,3) \times 2 \\
& =10,125 \mathrm{~kg} \cdot \mathrm{m}
\end{aligned}
$$

Nilai tegangan yang didapatkan dari analisis data yang sudah kita oleh adalah sebagai berikut:

$$
\begin{aligned}
\sigma & =\frac{F}{A}\left(m^{2}\right) \\
& =\frac{2,5}{95}=0,26 m^{2}
\end{aligned}
$$

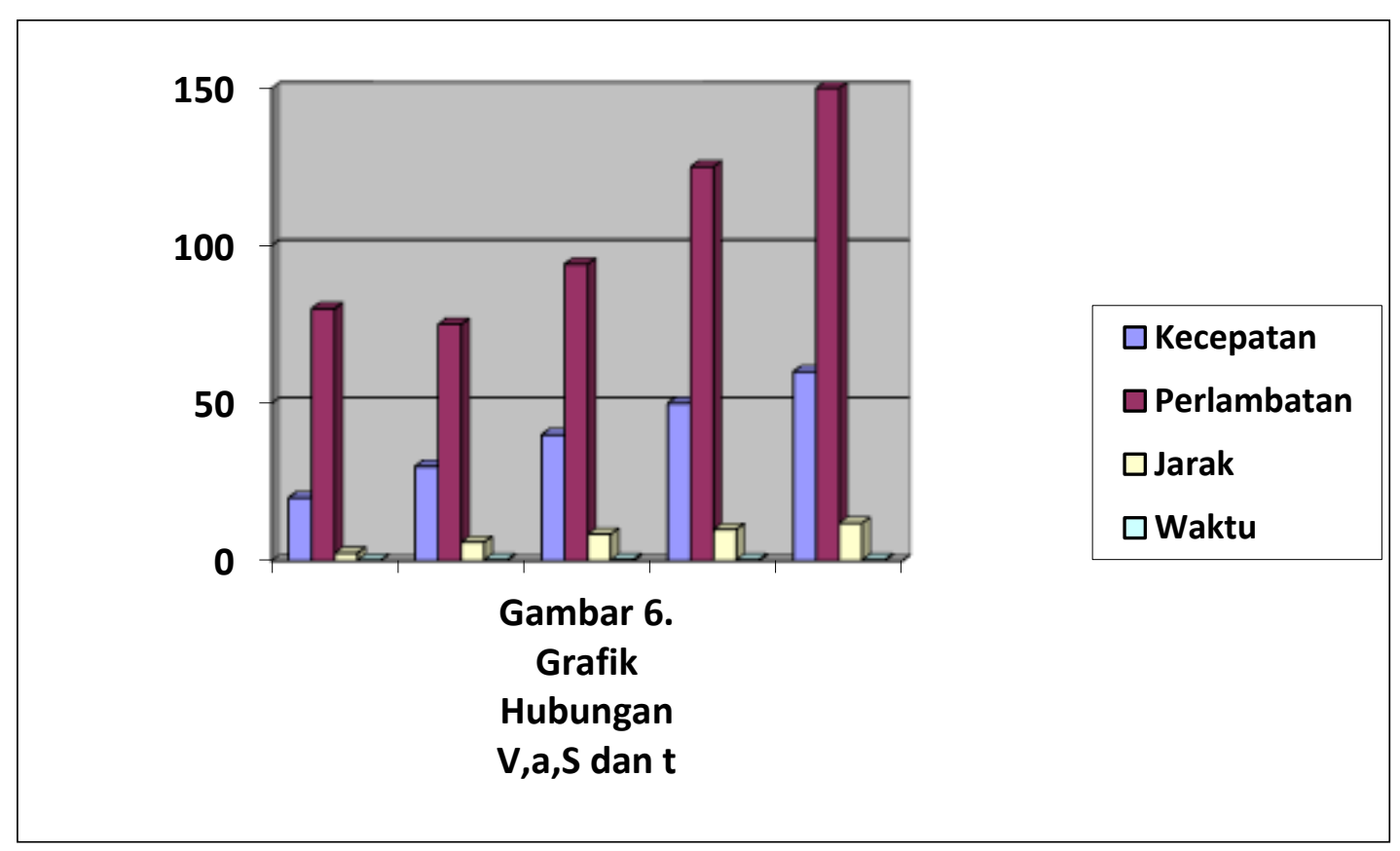




\section{KESIMPULAN}

Dari hasil penelitian yang telah dilakukan terhadap nilai perlambatan dan ketegangan pada Disch Brake maka didapatkan data dan analisis kesimpulan sebagai berikut:

1) Nilai perlambatan pengereman akan semakin tinggi jika kecepatan awal gokart ditambah.

2) Semakin nilai percepatan awal ditambah maka nilai perlambatan juga akan semakin naik.

3) Semakin panjang jarak pengereman maka waktu yang dibutuhkan juga semakin lama.

4) Efisiensi pengereman yang didapatkan antara gaya pengereman dengan berat pengereman sebesar $13,58 \%$.

5) Nilai tegangan disch brake yang dihasilkan adalah $0,26 \mathrm{~m}^{2}$.

\section{UCAPAN TERIMA KASIH}

Peneliti banyak mengucapkan terima kasih kepada semua pihak yang telah membantu, mendukung dan memberikan masukan baik ilmu, materi dan lain sebagainya sehingga penelitian pada pengereman Gokart dapat mendapatkan hasil dan bermanfaat bagi semua pembaca.

\section{DAFTAR PUSTAKA}

Hardianto,Ian siahaan., Yung,hoo sen,(2008). Kinerja rem tromol terhadap kinerja rem cakram kendaraan roda dua pada pengujian stasioner, jurusan teknik mesin universitas kristen petra, Surabaya

Meifal rusli dkk, 2010 "analisis getaran dan suara pada rem cakram saat beroperasi" seminar nasional tahunan teknik mesin (snttm) ke-9, universitas andalas.

M.M.Elhafid, D.D. Susilo, and P.J. Widodo, "Pengaruh bahan kampas rem terhadap respon getaran pada sistem rem cakram," Jurnal Teknik Mesin Indonesia, vol. 12, no. 1, pp. 1-7, April 2017.

Pemerintah Republik Indonesia (2012) Peraturan Pemerintah Nomor 55 tahun 2012 Tentang Kendaraan.

Panjaitan, H. 2018. Perancangan elemen mesin. http://id.scribd.com/document/377475721 /Hikma- Panjaitan-Perancangan-Elemen-Mesin112073073.

Sularso, Kiyokatsu suga. Dasar perencanaan dan pemilihan elemen mesin, jakarta 1994

Tripariyanto,A.Y \& Indrasari (2019) Disch Brake type of Braking System on rear Shaft of Gokart Daiho 7,5 Hp.Journal of Physic : Converence series Vol 1569. 